\title{
Optimization and software realization of SPC control of one enterprise
}

\author{
Lu Jianfeng, He Peng \\ CIMS Research Center TongJi University, Shanghai, China \\ lujianfeng@tongji.edu.cn \\ 154195832@qq.com
}

\begin{abstract}
Keywords: Electronic Power Steering, SPC control chart, weighted optimization control, software
\end{abstract} realization.

\begin{abstract}
SPC (Statistical process control) chart is widely used as a useful quality control tool during production.It can monitor and refect the stability of the process of production.But the traditional SPC is not sensitive to small warps, especially in customized fields. Research the optimized SPC control chart, compare with the traditional one. Analyze the function of SPC control system and realize it.
\end{abstract}

\section{Introduction}

With the development of economy, the production of auto parts is processing the changing from large scales to smaller and customized modes. In this situation the traditional SPC control technology is facing the problems of small sample size and not sensitive enough and so on. It can hardly direct production property. Research on the optimization of SPC control and software realize based on the EPS (Electronic Power Steering) production line of one enterprise.

\section{EPS}

EPS (Electronic Power Steering), use the power generated by motor to corporate with drivers to change direction. Different mode of auto has different structures of EPS. So the production of EPS is a typical customized process. Take the output voltage of torque sensor as example to collect data and discuss the weighted optimization control.

\section{Traditional SPC Control Chart}

SPC control theory was raised by Dr.Walter A.Shewhart in 1924. Now there are many kinds of control charts such as $\overline{\mathrm{X}}-\mathrm{R}$ chart, $\mathrm{X}-\mathrm{S}, \mathrm{P}$ chart and so on. $\overline{\mathrm{X}}-\mathrm{R}$ chart is the most widely used one.

$\mathrm{X}$ Control chart is used to observe the change of mean value $(\mu)$ of normal distribution and $\mathrm{R}$ control chart is used to observe the change of standard deviation $(\sigma)$ of normal distribution. Using $\overline{\mathrm{X}}$-R control can find the change of normal distribution and points which are out of control.

Assume that the whole process obeys $\mathrm{N}(\mu, \sigma)$, then $\overline{\mathrm{X}}$ obeys the distribution of $\mathrm{N}(\mu, \sigma / \sqrt{\mathrm{N}}), \mathrm{R}$ obeys $\left(d_{2} \sigma, d_{2} \sigma\right)\left(d_{2}, d_{2}\right.$ is factors changing with $\left.n\right)$. The sample group $i \in[1, m]$, then the $j_{\text {th }}$ measurement result of group $i$ is expressed as $X_{i f \mid}, j \in\left[\begin{array}{ll}1, & n\end{array}\right]$, the mean value of the $i_{\text {th }}$ group is $\overline{X_{n}}$, mean value of whole sample groups is $\bar{X}$. The range of $i_{\text {th }}$ group is $R_{i}$, mean range of all samples groups is $\mathbf{R}$ then ${ }^{[1]}$

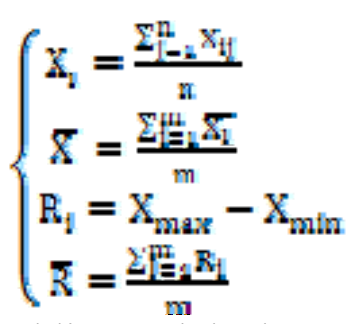

UCL, CL and LCL (upper limit, central line and the lower limit of $\overline{\mathrm{X}}$ control chart) are defined as 


$$
\left\{\begin{array}{l}
U C L_{\bar{S}}=\bar{X}+A_{2} \bar{R} \\
\mathrm{CL}_{\mathrm{S}}=\bar{X} \\
\mathrm{LCL}_{\mathrm{S}}=\mathrm{X}-\mathrm{A}_{2} \bar{R}
\end{array}\right.
$$

UCL, CL and LCL (upper limit, central line and the lower limit of R control chart) are defined ${ }^{[2]}$

$$
\left\{\begin{array}{l}
U L_{R}=D_{4} \bar{R} \\
C L_{R}=\mathrm{R} \\
L C L_{R}=D_{3} \bar{R}
\end{array}\right.
$$

$A_{2}, D_{w}, D_{4}$ are factors that can be got from related tables.

When create the $\overline{\mathrm{X}}-\mathrm{R}$ control chart, draw 3 lines UCL, CL and LCL firstly then draw $\overline{\mathrm{X}}$ or $\overline{\mathrm{R}}$ of every group. At last judge that if there are abnormal points from the control chart.

The traditional $\overline{\mathrm{X}}-\mathrm{R}$ is used based on the present data and have nothing to do with previous data. This method abandons lots of historic information, lead to low precision and is blunt to small changes.

\section{Weighted Optimization SPC Control Chart}

The main idea of the optimized $\overline{\mathrm{X}}-\mathrm{R}$ control chart is: data got recently can reflect more quality information so they will have bigger weight otherwise the weight is smaller. In this way the $\overline{\mathrm{X}}-\mathrm{R}$ control chart can be more sensitive and predict the abnormal points advanced.

Set weight to every variable, and the sum of all these weight is $1, W_{1}$ is the weight of the $i_{\text {th }}$ measured data, $\mathrm{X}_{\mathrm{i}}$ is the $\mathrm{i}_{\text {th }}$ measured data, then data after weighted is $\mathrm{W}_{\mathrm{I}} \mathrm{X}_{\mathrm{L}}, \mathrm{X}_{t+1}$ the estimated value of $(t+1)_{\text {th }}$ point can be expressed as the linear combination of the previous $t$ weighted measured data and the 1 st weighted predictive result ${ }^{[3]}$.

\section{$\mathrm{X}_{\mathrm{t}+1}=$}

$\beta \mathrm{x}_{\mathrm{t}}\left|\beta(1 \quad \beta) \mathrm{x}_{\mathrm{t}-1}\right| \cdots\left|\beta(1 \quad \beta)^{\mathrm{k}} \mathrm{X}_{\mathrm{t}-\mathrm{k}}\right| \cdots\left|\beta(1 \quad \beta)^{\mathrm{t}-1} \mathrm{x}_{1}\right|\left(\begin{array}{ll}1 & \beta\end{array}\right) \mathrm{X}_{\mathrm{r}}$

weight of every data is:

Because

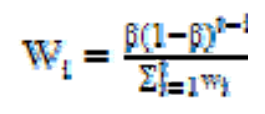

$$
\beta+\beta(1-\beta)+\cdots \beta(1-\beta)^{k}+\cdots+\beta(1-\beta)^{t-1}+(1-\beta)^{t}=1
$$

So for every $\cap \in[0,1]$, there is a group of $W_{1}, i \in[1, t]$ makes the formula $(6)$ reasonable weighted mean value and range as

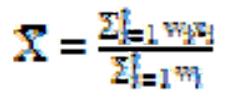

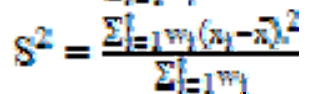

$$
\begin{aligned}
& \zeta=\frac{\sum E_{i} \mathrm{~S}}{\mathrm{M}}
\end{aligned}
$$

Limits after weighted of $\overline{\mathrm{X}}$ control chart is

$$
\left\{\begin{array}{l}
\mathrm{UCL}_{\mathrm{X}}=\overline{\mathrm{X}}+\frac{3}{\sqrt{2}} \mathrm{~S} \\
\mathrm{CL}_{\mathrm{X}}=\mathrm{X} \\
\mathrm{LCL}_{\mathrm{X}}=\mathrm{X}-\frac{3}{\sqrt{2}} \mathrm{E}
\end{array}\right.
$$

Limits after weighted of $\mathrm{R}$ control chart is

$$
\left\{\begin{array}{l}
\mathrm{UCL}_{\mathrm{R}}=\left(\mathrm{d}_{2}+3 \mathrm{~d}_{3}\right) \mathrm{S} \\
\mathrm{CL}_{\mathrm{R}}=\mathrm{d}_{2} \mathrm{~S} \\
\mathrm{LCL_{ \textrm {R } }}=\left(\mathrm{d}_{2}-3 \mathrm{~d}_{3}\right) \mathrm{S}
\end{array}\right.
$$

\section{Actual Sample Analyze}


Take the output voltage of torque sensor as example and collect 20 sets data. The $\overline{\mathrm{X}}$ control chart before and after optimization as Fig1 and Fig2 show

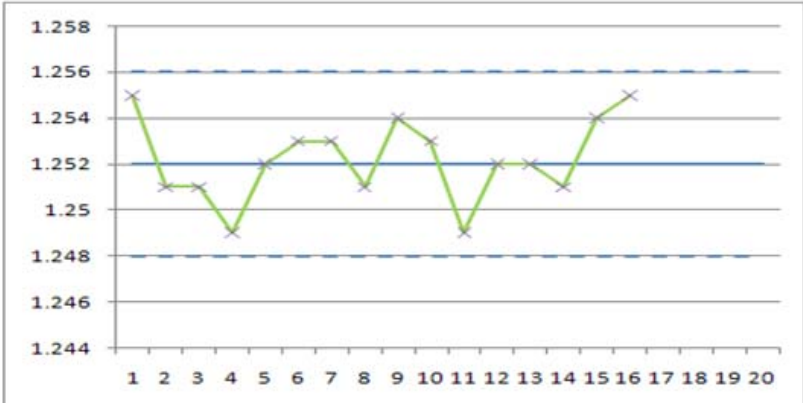

Fig1

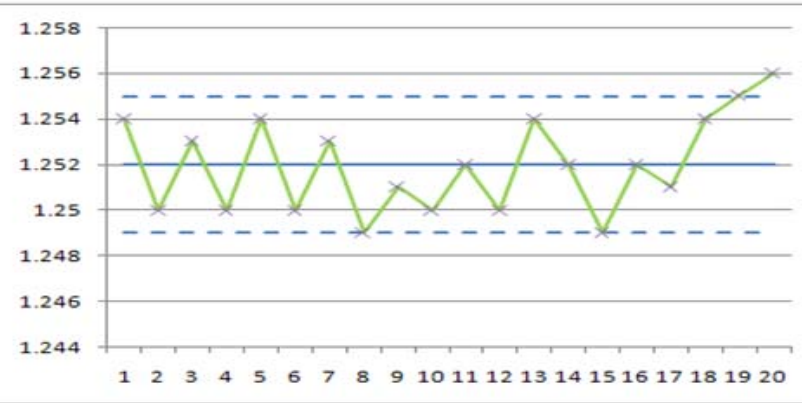

Fig2

Fig1 is the traditional control chart. Fig2 is control chart after optimization. It's easily to find that last several points are processing an additional trend. In the traditional chart there is no abnormal but in the chart after optimization the $20^{\text {th }}$ point is already out of control line. So we can come to the conclusion that the chart is more sensitive after optimized.

\section{Software Function Analyze}

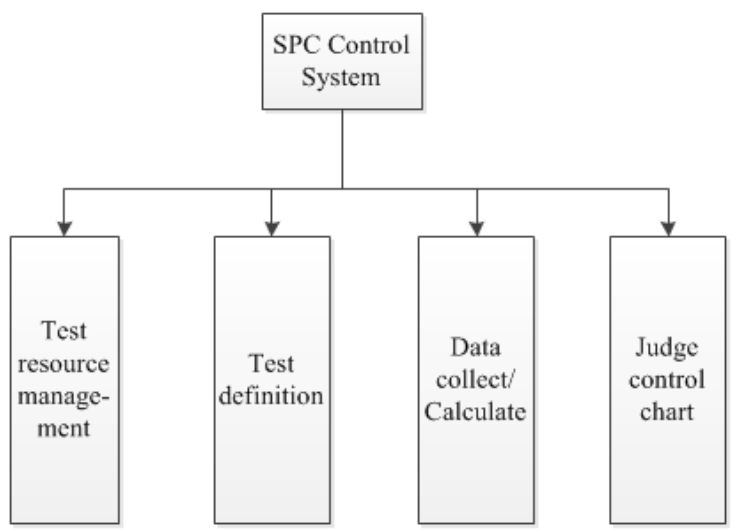

The function module as Fig3 shows ${ }^{[4]}$

Fig3

Test resource management: This module is to manage /record the resources used to collect quality data. The resources can be a single machine or a group of machines.

Test definition: In this part, engineers will set up related quality test requirement such as test items, test method, the frequency of test and so on.

Data collect/calculate: Collect data as related document's requirement. Then calculate the mean values, ranges, and limits after optimized.

Judge control chart: The judgment of points that out of control limits is a very important function of SPC software. Analyze the distribution of points of control chart When generate the chart. Judge whether the processes are under control and detect the abnormal points in time. When abnormal points are found alarms will be given to operators. So they can take measurements to solve problems as soon as possible.

\section{Realization of Software}

$\mathrm{C} / \mathrm{S}$ (Client/Server) structure has good performance of interactivity, safety and real time. And the 3 layers $\mathrm{C} / \mathrm{S}$ structure is better than 2 layers in flexibility, speed of response of system and network flow ${ }^{[5]}$. So take the 3 layers $\mathrm{C} / \mathrm{S}$ structure to realize the system. Use .net as developing tool and SQLserver2008 as database. Use ADO.NET to connect database. Use drawing tools to realize the control chart and virtual interface. 


\section{Conclusion}

Compared the weighted control chart with the traditional control char, the weighted chart is more sensitive to tiny changes. Though the computing of weighted optimization is complicate, it has no special requirement of judgment and easily to be realized. So the weighted control chart can monitor and direct the process of production better.

\section{Acknowledgements}

This work was financially supported by the Major Program of National Natural Science Foundation of China (No.61034004): The theory and method of optimized scheduling based on data of complicate production process.

\section{References}

[1] Lin Ma, Zhen He: 6 sigma management, Renmin University of China Publishers (2002), p39-45

[2] Liu WenQing: Process control technology,BeiJing University Publisher(2003), p125.

[3] Jian Chen: Application research of Statistical process control (SPC) in Quality Control (2007) p.35-36

[4]Zhang GenBao:Quality tracking system based on MES and CAPP,Computer maufacturing system(2010), p 349-355.

[5] Wei GaoShan: Analyze and application of three laiers Client/Server structure,Computer Engineering and application (2000) p. 119-120 